\title{
Plasma levels and diagnostic utility of VEGF, MMP-9, and TIMP-I in the diagnosis of patients with breast cancer
}

This article was published in the following Dove Press journal:

OncoTargets and Therapy

24 February 2016

Number of times this article has been viewed

\author{
Sławomir Ławicki' \\ Monika Zajkowska' \\ Edyta Katarzyna Głażewska² \\ Grażyna Ewa Będkowska ${ }^{3}$ \\ Maciej Szmitkowski' \\ 'Department of Biochemical \\ Diagnostics, ${ }^{2}$ Laboratory of \\ Esthetic Medicine, ${ }^{3}$ Department of \\ Hematological Diagnostics, Medical \\ University of Bialystok, Bialystok, \\ Poland
}

\begin{abstract}
Vascular endothelial growth factor (VEGF), matrix metalloproteinase-9, and tissue inhibitor of metalloproteinase-1 may play a role in the pathogenesis of cancer disease. We investigated their levels and utility in comparison to cancer antigen (CA) 15-3 in patients with breast cancer $(\mathrm{BC})$ and in relation to the control groups. The study included 100 women with $\mathrm{BC}, 50$ patients with benign breast tumor, and 50 healthy women. The plasma levels of the tested parameters were determined using enzyme-linked immunosorbent assay, while CA 15-3 with chemiluminescent microparticle immunoassay. The results demonstrated significant differences in the concentration of the tested parameters and CA 15-3 between groups of patients with BC and healthy patients or patients with benign breast tumor. The plasma levels of VEGF and tissue inhibitor of metalloproteinase-1 were significantly higher in advanced tumor stages. The tested parameters were comparable to CA 15-3 values of the diagnostic sensitivity, specificity, the predictive values of positive and negative test results, and the area under the receiver-operating characteristic curve. The combined use of the tested parameters with CA 15-3 resulted in the increase in sensitivity, negative predictive value, and area under the receiver-operating characteristic curve, especially in the combination of VEGF with tumor marker (84\%, 73\%, 0.888, respectively). These findings suggest the usefulness of the tested parameters in the diagnosis of BC. VEGF, especially in combination with CA 15-3, showed the highest usefulness in the diagnosis of early BC.
\end{abstract}

Keywords: diagnostic panel, gelatinase B, growth factor, tumor markers, CA 15-3

\section{Introduction}

Breast cancer (BC) is the most common malignancy in women and the second leading cause of their death in the world. ${ }^{1}$ It is associated with the fact that the available tumor markers show low sensitivity (SE), and thus, the cancer is undetected in early stages. Considering the increasing number of cases, early diagnosis is vital, especially in the initial stages of the tumor. ${ }^{2}$ The substantial progress in this field has been made by screening methods that include ultrasound, computed tomography, or magnetic resonance imaging. However, in the case of small lesions, these methods are not very effective. That is why the search for new diagnostic methods that could be helpful in early cancer detection is needed.

Tumor markers are especially useful in monitoring treatment and in the detection, location, or identification of metastatic stage of cancer and early detection of its recurrence. At present, such diagnostic biomarkers in patients with BC comprise several circulating mucinous markers, including cancer antigen (CA) 15-3, carcinoembryonic antigen, and cytokeratin-19 fragments (CYFRA 21.1). ${ }^{2-4}$ Their prognostic relevance is supported by a
Correspondence: Monika Zajkowska Department of Biochemical Diagnostics, Medical University of Bialystok, Waszyngtona 15A, I5-269 Bialystok, Poland

Email monika@zajkowska.com (c) (1) (5) 2016 tawicki et al. This work is published and licensed by Dove Medical Press Limited. The full terms of this license are available at https://www.dovepress.com/terms.php cC) and incorporate the Creative Commons Attribution - Non Commercial (unported, v3.0) License (http://creativecommons.org/licenses/by-nc/3.0/). By accessing the work you hereby accept the Terms. Non-commercial uses of the work are permitted without any further permission from Dove Medical Press Limited, provided the work is properly attributed. For permission for commercial use of this work, please see paragraphs 4.2 and 5 of our Terms (https://www.dovepress.com/terms.php). 
number of studies, but these markers have low SE and specificity (SP) in less-advanced stages of cancer, which is why they are unsuitable for screening. ${ }^{5}$ The new candidates for tumor markers may be cytokines, for example, vascular endothelial growth factor (VEGF) ${ }^{6}$ and macrophage-colony stimulating factor, ${ }^{7}$ matrix metalloproteinases (MMPs), ${ }^{8,9}$ and their inhibitors (tissue inhibitors of metalloproteinases [TIMPs]). ${ }^{9}$

VEGF is considered to be an important factor in promoting angiogenesis in many pathological conditions, including malignant processes. It promotes $\mathrm{BC}$ progression by inducing angiogenesis and lymphangiogenesis. ${ }^{10,11} \mathrm{~A}$ high expression of VEGF and its messenger RNA have been found in BC cells. ${ }^{11,12}$

Matrix metalloproteinase-9 (MMP-9, also known as gelatinase B) is produced by keratinocytes, monocytes, leukocytes, and a variety of malignant cells and plays an important role in BC progression. ${ }^{13-15}$ It is involved in the degradation of the extracellular matrix that enhances breast metastasis. ${ }^{16,17}$ In tumor, MMP-9 destroys collagen (type IV) in the vascular basal membrane near the tumor cells that invade the surrounding tissues and contribute to metastasis. ${ }^{18,19}$

Tissue inhibitor of metalloproteinase-1 (TIMP-1) is a naturally occurring glycoprotein that has been demonstrated in several types of cancer, including breast tumor. ${ }^{20-22}$ High levels of TIMP-1 in primary tumor tissue are associated with a decreased objective response to chemotherapy ${ }^{23}$ and endocrine therapy in patients with metastatic BC..$^{24,25}$

In our research commenced in 2001, we have been searching for new biochemical parameters that could become biochemical markers in many types of tumors, for instance, $\mathrm{BC},{ }^{26,27}$ ovarian cancer, ${ }^{28,29}$ cervical cancer, ${ }^{30}$ endometrial cancer, ${ }^{31}$ lung cancer, or colon cancer.

The aim of this particular study was to determine the plasma levels of VEGF, MMP-9, its inhibitor - TIMP-1, and CA 15-3 (comparative tumor marker) in patients with BC in relation to the control groups (consisting of patients with benign breast tumor and healthy women). These data after closer examination may be considered as a new diagnostic panel used in the diagnosis of patients with BC.

\section{Material and methods Patients}

Table 1 shows the tested groups. The study included 100 women with $\mathrm{BC}$ diagnosed by the oncology group. The patients with $\mathrm{BC}$ were treated in the Department of Oncology, Medical University, Białystok, Poland. Tumor classification and staging were done in accordance with the International Union Against Cancer Tumor-Node-Metastasis
Table I Characteristics of patients with breast cancer and control groups: benign breast tumor and healthy women

\begin{tabular}{|c|c|}
\hline Study group & Number of patients \\
\hline Patients with breast cancer & 100 \\
\hline \multicolumn{2}{|l|}{ Type } \\
\hline Adenocarcinoma ductale & 100 \\
\hline Median age (range), years & $56(37-78)$ \\
\hline \multicolumn{2}{|l|}{ Tumor stage } \\
\hline $\mathrm{I}-\mathrm{T}_{1} \mathrm{~N}_{0} \mathrm{M}_{0}$ & 29 \\
\hline$\| \mathrm{A}-\mathrm{T}_{2} \mathrm{~N}_{0} \mathrm{M}_{0}$ & 7 \\
\hline$\| \mathrm{B}-\mathrm{T}_{2} \mathrm{~N}_{1} \mathrm{M}_{0}$ & 10 \\
\hline$-\mathrm{T}_{3} \mathrm{~N}_{0} \mathrm{M}_{0}$ & 7 \\
\hline IIIA $-\mathrm{T}_{2} \mathrm{~N}_{2} \mathrm{M}_{0}$ & 5 \\
\hline$-\mathrm{T}_{3} \mathrm{~N}_{1} \mathrm{M}_{0}$ & 7 \\
\hline$I I I B-T_{4} N_{2} M_{0}$ & 6 \\
\hline$-\mathrm{T}_{4} \mathrm{~N}_{3} \mathrm{M}_{0}$ & 6 \\
\hline IV (metastases) & 23 \\
\hline \multicolumn{2}{|l|}{ Menopausal status } \\
\hline Premenopausal & 41 \\
\hline Postmenopausal & 59 \\
\hline Patients with benign breast tumor & 50 \\
\hline \multicolumn{2}{|l|}{ Type } \\
\hline Adenoma & 23 \\
\hline Papilloma intraductale & 6 \\
\hline Fibroadenoma & 16 \\
\hline Mastopatia & 5 \\
\hline Median age (range), years & $47(20-76)$ \\
\hline \multicolumn{2}{|l|}{ Menopausal status } \\
\hline Premenopausal & 19 \\
\hline Postmenopausal & 31 \\
\hline Healthy women & 50 \\
\hline Median age (range), years & $4 \mid(2 \mid-74)$ \\
\hline \multicolumn{2}{|l|}{ Menopausal status } \\
\hline Premenopausal & 24 \\
\hline Postmenopausal & 26 \\
\hline
\end{tabular}

classification. The BC histopathology was established in all cases with tissue biopsy of mammary tumor or after surgery from tumor cancer tissues (all patients with adenocarcinoma ductale). The pretreatment staging procedures included physical and blood examinations, mammography, mammary ultrasound scanning, breast core biopsies, and chest X-rays.

In addition, radioisotopic bone scans, examination of bone marrow aspirates, and computed tomography scans of brain and chest were performed when necessary. None of the patients had received chemo- or radiotherapy before blood sample collection.

The control groups included 50 patients with benign breast tumor and 50 healthy untreated women who underwent mammary gland examination performed by a gynecologist prior to blood sample collection. In addition, mammary ultrasound scanning was performed in all cases. The benign 
breast tumor histopathology was established in all cases by tissue biopsy of mammary tumor or after surgery.

The study was approved by the local Ethics Committee in Medical University of Bialystok (R-I-002/239/2014). All the patients gave their written informed consent for the examination.

\section{Ethical declaration}

This work was conducted in accordance with the Declaration of Helsinki (1964).

\section{Biochemical analyses}

Venous blood samples were collected from each patient into a heparin sodium tube, centrifuged $1,000 \mathrm{rpm}$ for 15 minutes to obtain plasma samples, and stored at $-85^{\circ} \mathrm{C}$ until assayed. The tested parameters were measured with the enzyme-linked immunosorbent assay (VEGF, MMP-9, TIMP-1; Quantikine Human Immunoassay, R\&D Systems, Inc., Minneapolis, MN, USA) and chemiluminescent microparticle immunoassay (CA 15-3; Abbott Laboratories, Abbott Park, IL, USA) according to the manufacturer's protocols. In enzyme-linked immunosorbent assay, duplicate samples were assessed for each patient.

The intra-assay coefficient of variation of CA 15-3 is reported to be $2.2 \%$ at a mean concentration of $27.0 \mathrm{U} / \mathrm{mL}$, standard deviation $[\mathrm{SD}]=0.6$. VEGF is reported to be $4.5 \%$ at a mean concentration of $235 \mathrm{pg} / \mathrm{mL}, \mathrm{SD}=10.6$. MMP-9 is reported to be $1.9 \%$ at a mean concentration of $2.04 \mathrm{ng} / \mathrm{mL}$, $\mathrm{SD}=0.039$, and TIMP- 1 is reported to be $3.9 \%$ at a mean concentration of $1.27 \mathrm{ng} / \mathrm{mL}, \mathrm{SD}=0.05$.

The inter-assay coefficient of variation of CA $15-3$ is reported to be $2.6 \%$ at a mean concentration of $27.0 \mathrm{U} / \mathrm{mL}$, $\mathrm{SD}=0.7$. VEGF is reported to be $7.0 \%$ at a mean concentration of $250 \mathrm{pg} / \mathrm{mL}, \mathrm{SD}=17.4$. MMP-9 is reported to be $7.8 \%$ at a mean concentration of $2.35 \mathrm{ng} / \mathrm{mL}, \mathrm{SD}=0.184$, and TIMP-1 is reported to be $3.9 \%$ at a mean concentration of $1.28 \mathrm{ng} / \mathrm{mL}, \mathrm{SD}=0.05$.

\section{Statistical analysis}

We defined the following diagnostic criteria: SE, SP and the predictive value of a positive (PPV) and negative (NPV) test result. Moreover, we defined the receiver-operating characteristic (ROC) curve for all the tested parameters and Spearman's rank correlation between the tested parameters and CA 15-3.

The statistical analysis was performed using STATISTICA 8.0 PL Program. The preliminary statistical analysis (chi-square test) revealed that the distribution of the levels of the tested parameters failed to follow normal distribution. Consequently, the Mann-Whitney $U$-test was used for statistical analysis between patients with cancer and control groups. Additionally, statistical analysis between the groups with different stages of $\mathrm{BC}$ was performed with the use of Kruskal-Wallis test and a multivariate analysis of various data with the post hoc Dwass-Steele-Crichlow-Flinger test. The data were presented as a median and a range. The Spearman's rank correlation was used in the correlation analysis. Statistically significant differences were defined as comparisons resulting in $P<0.05$.

Diagnostic SE, SP, and the PPV and NPV test result were calculated using the following cutoff value: 95th percentile from the control group (calculated from healthy blood donors): VEGF: 121.98 pg/mL; MMP-9: 384 ng/mL; TIMP-1: $258.61 \mathrm{ng} / \mathrm{mL}$; and CA 15-3: $23.65 \mathrm{U} / \mathrm{mL}$. The construction of the ROC curves was performed using GraphRoc program for Windows and the area under the ROC curve (AUC) were calculated.

\section{Results}

Table 2 shows the median and the range of plasma levels of the investigated parameters and CA 15-3 in the tested groups. The medians of VEGF (131.54 pg/mL) and MMP-9 $(279.86 \mathrm{ng} / \mathrm{mL})$ levels, similarly to the level of the commonly accepted tumor marker CA 15-3 (26.53 U/mL), in the total group of patients with $\mathrm{BC}$ were significantly higher when compared to the healthy women $(P<0.001, P=0.005$, and $P<0.001$, respectively). Additionally, the median levels of VEGF and TIMP-1 in the total BC group were statistically higher than in the group of patients with benign breast tumor ( $P=0.04, P<0.001$, respectively).

Also, we noticed no statistical differences between the concentrations of MMP-9 in patients with benign breast tumor and healthy controls. That is very important since higher MMP-9 levels can be observed only in patients with BC.

Similarly, we observed statistically significantly higher concentrations of VEGF in all the analyzed groups in relation to the stage of $\mathrm{BC}$ advancement compared to healthy women $(P<0.05$ in all cases). Significantly higher concentrations of MMP-9 in stages III and IV $(P=0.04$ and $P=0.05$, respectively) and TIMP-1 in stage III $(P=0.017)$ were also observed. We noticed similar data for CA 15-3 ( $P=0.005-$ II and $P<0.001-$ in III and IV stages, respectively). Moreover, plasma concentrations of the tested parameters (with the exception of MMP-9) were significantly higher in more advanced stages (III-IV) than those found in the early stages (I-II) $(P<0.05$ in all cases).

The Spearman's rank correlation was used in the dependence analyses between the investigated parameters and 
Table 2 Plasma levels of tested parameters and CA 15-3 in patients with breast cancer and in control groups

\begin{tabular}{|c|c|c|c|c|}
\hline Groups tested & MMP-9 (ng/mL) & TIMP-I (ng/mL) & VEGF $(p g / m L)$ & CA I5-3 (U/mL) \\
\hline \multicolumn{5}{|c|}{ Breast cancer (median, range) } \\
\hline \multirow[t]{3}{*}{ Stage I } & & & $*$ & \\
\hline & 267.83 & 98.80 & 109.96 & 20.02 \\
\hline & $46.81-736.92$ & $44.4 I-334.16$ & $12.98-700.02$ & $7.17-34.38$ \\
\hline \multirow[t]{3}{*}{ Stage II } & & $* *$ & $*$ & $*$ \\
\hline & 274.04 & 129.79 & 115.89 & 23.32 \\
\hline & $93.65-830.12$ & $33.18-346.75$ & $44.47-750.66$ & $7.82-32.31$ \\
\hline \multirow[t]{3}{*}{ Stage III } & * & $* / * * / * * *$ & $* / * * / * * *$ & $* / * * *$ \\
\hline & 360.00 & 198.23 & 220.48 & 34.12 \\
\hline & $50.91-840.02$ & $87.05-440.69$ & $38.55-1,051.00$ & $17.50-167.87$ \\
\hline \multirow[t]{3}{*}{ Stage IV } & $*$ & $* *$ & $*$ & $* / * * / * * *$ \\
\hline & 273.12 & 162.25 & 161.47 & 74.41 \\
\hline & $52.83-800.09$ & $4.58-438.49$ & $9.02-469.90$ & $18.50-250.45$ \\
\hline \multirow[t]{3}{*}{ Total group } & $*$ & $* *$ & $* / * *$ & $*$ \\
\hline & 279.86 & 147.66 & 131.54 & 26.53 \\
\hline & $46.8 I-840.02$ & $4.58-440.69$ & $9.02-1,051.00$ & $7.17-250.45$ \\
\hline \multicolumn{2}{|c|}{ Control groups (median, range) } & $* * * *$ & $* * * *$ & $* * * *$ \\
\hline \multirow[t]{2}{*}{ Benign breast tumor } & 209.37 & 74.67 & 83.12 & 25.21 \\
\hline & $36.10-840.12$ & $6.68-157.58$ & $9.02-970.14$ & $12.11-48.28$ \\
\hline \multirow[t]{2}{*}{ Healthy women } & 181.05 & 123.72 & 37.01 & 15.24 \\
\hline & $65.24-421.36$ & $34.57-332.38$ & $4.63-180.28$ & $6.8 I-27.57$ \\
\hline
\end{tabular}

Notes: *Statistically significant when patients with BC compared with healthy women. **Statistically significant when patients with BC compared with benign breast tumor group. ***Statistically significant when patients with BC stage III or IV compared with patients with BC stage I or II. ****Statistically significant when patients with benign breast tumor compared with healthy women.

Abbreviations: CA, cancer antigen; MMP-9, matrix metalloproteinase-9; TIMP-I, tissue inhibitor of metalloproteinase-I; VEGF, vascular endothelial growth factor; $\mathrm{BC}$, breast cancer.

CA 15-3 (data not shown). We observed a significant positive correlation between TIMP-1 with CA 15-3 concentrations in the total group of $\mathrm{BC}(R=0.28 ; P=0.015)$ and in stage $\mathrm{I}$ of cancer $(R=0.52 ; P=0.014)$. Also, a correlation between VEGF with TIMP-1 in stage III of cancer was observed ( $R=0.62 ; P=0.004)$.

Table 3 shows the following diagnostic criteria: SE, SP, PPV, and NPV in patients with BC. We indicated that the
SE of the tested parameters in the total cancer group was the highest for CA 15-3 (65\%) and higher than for VEGF (61\%), MMP-9 (37\%), and TIMP-1 (17\%). The combined use of the tested parameters with antigen CA 15-3 resulted in an increase in SE values (84\%, 76\%, and 67\%, respectively). A maximum value of the total $\mathrm{BC}$ group was obtained for the combination of all the studied parameters (87\%). Among all parameters, the highest SE in stage I of cancer was observed

Table 3 Diagnostic criteria of tested parameters and in combined analysis with CA 15-3 in patients with breast cancer

\begin{tabular}{|c|c|c|c|c|c|c|}
\hline \multirow[t]{2}{*}{ Tested parameters } & \multirow{2}{*}{$\begin{array}{l}\text { Diagnostic } \\
\text { criteria (\%) }\end{array}$} & \multicolumn{5}{|c|}{ Breast cancer } \\
\hline & & Stage I & Stage II & Stage III & Stage IV & Total group \\
\hline \multirow[t]{4}{*}{ MMP-9 } & SE & 26 & 36 & 46 & 41 & 37 \\
\hline & SP & 96 & 96 & 96 & 96 & 96 \\
\hline & PPV & 72 & 79 & 82 & 81 & 95 \\
\hline & NPV & 73 & 76 & 77 & 77 & 44 \\
\hline \multirow[t]{4}{*}{ TIMP-I } & SE & 6 & 6 & 41 & 16 & 17 \\
\hline & SP & 96 & 96 & 96 & 96 & 96 \\
\hline & PPV & 34 & 34 & 81 & 61 & 88 \\
\hline & NPV & 68 & 68 & 77 & 70 & 37 \\
\hline \multirow[t]{4}{*}{ VEGF } & SE & 51 & 56 & 66 & 71 & 61 \\
\hline & SP & 96 & 96 & 96 & 96 & 96 \\
\hline & PPV & 84 & 86 & 88 & 89 & 97 \\
\hline & NPV & 80 & 82 & 85 & 87 & 55 \\
\hline \multirow[t]{4}{*}{ CA I5-3 } & SE & 31 & 56 & 86 & 86 & 65 \\
\hline & $\mathrm{SP}$ & 96 & 96 & 96 & 96 & 96 \\
\hline & PPV & 76 & 86 & 90 & 90 & 97 \\
\hline & NPV & 74 & 82 & 94 & 94 & 58 \\
\hline
\end{tabular}


Table 3 (Continued)

\begin{tabular}{|c|c|c|c|c|c|c|}
\hline \multirow[t]{2}{*}{ Tested parameters } & \multirow{2}{*}{$\begin{array}{l}\text { Diagnostic } \\
\text { criteria (\%) }\end{array}$} & \multicolumn{5}{|c|}{ Breast cancer } \\
\hline & & Stage I & Stage II & Stage III & Stage IV & Total group \\
\hline \multirow[t]{4}{*}{ MMP-9 + CA I5-3 } & SE & 41 & 71 & 100 & 91 & 76 \\
\hline & SP & 90 & 90 & 90 & 90 & 90 \\
\hline & PPV & 68 & 79 & 84 & 83 & 95 \\
\hline & NPV & 76 & 87 & 100 & 96 & 65 \\
\hline \multirow[t]{4}{*}{ TIMP-I + CA I5-3 } & SE & 36 & 56 & 91 & 86 & 67 \\
\hline & $\mathrm{SP}$ & 90 & 90 & 90 & 90 & 90 \\
\hline & PPV & 65 & 74 & 83 & 82 & 94 \\
\hline & NPV & 74 & 81 & 96 & 93 & 58 \\
\hline \multirow[t]{4}{*}{ VEGF + CA I5-3 } & SE & 61 & 76 & 100 & 96 & 84 \\
\hline & $\mathrm{SP}$ & 90 & 90 & 90 & 90 & 90 \\
\hline & PPV & 76 & 80 & 84 & 84 & 95 \\
\hline & NPV & 83 & 89 & 100 & 98 & 73 \\
\hline \multirow[t]{4}{*}{ VEGF + MMP-9 + CA I5-3 } & SE & 66 & 81 & 100 & 96 & 86 \\
\hline & $\mathrm{SP}$ & 85 & 85 & 85 & 85 & 85 \\
\hline & PPV & 69 & 74 & 78 & 77 & 92 \\
\hline & NPV & 84 & 89 & 100 & 98 & 75 \\
\hline \multirow[t]{4}{*}{ VEGF + TIMP-I + CA I5-3 } & SE & 66 & 76 & 100 & 96 & 85 \\
\hline & SP & 85 & 85 & 85 & 85 & 85 \\
\hline & PPV & 69 & 72 & 77 & 78 & 93 \\
\hline & NPV & 84 & 88 & 100 & 98 & 73 \\
\hline \multirow[t]{4}{*}{ MMP-9 + TIMP-I + VEGF + CA I5-3 } & SE & 71 & 81 & 100 & 96 & 87 \\
\hline & SP & 80 & 80 & 80 & 80 & 80 \\
\hline & PPV & 65 & 68 & 72 & 71 & 91 \\
\hline & NPV & 85 & 90 & 100 & 98 & 75 \\
\hline
\end{tabular}

Abbreviations: CA, cancer antigen; MMP-9, matrix metalloproteinase-9; TIMP-I, tissue inhibitor of metalloproteinase-I; VEGF, vascular endothelial growth factor; PPV, positive predictive value; NPV, negative predictive value; SE, sensitivity; SP, Specificity.

for VEGF (51\%), in stage II of BC - VEGF and CA 15-3 (56\% both), and in stages III and IV of BC - CA 15-3 (86\% both). The combined use of the tested parameters with antigen CA 15-3 resulted in an increase in SE in every stage of BC. The highest values were obtained for the combination of VEGF or MMP-9 with CA 15-3 (III - 100\% both; IV - 96\% and $91 \%$, respectively).

The diagnostic SP for VEGF, MMP-9, TIMP-1, and CA 15-3 showed very high and equal values (for all parameters 96\%).

The PPV in the total group of patients with $\mathrm{BC}$ was the highest for VEGF and CA 15-3 (97\% both) in comparison to MMP-9 (95\%) and TIMP-1 (88\%). Among all the tested parameters, the highest PPV values in stage I of cancer were observed for VEGF (84\%), in stage II of BC - VEGF and CA 15-3 (86\% both), and in stages III and IV of BC - CA 15-3 (90\% both). The combined use of the tested parameters with CA 15-3 resulted in a decrease in the PPV range in the combination with VEGF in all BC groups and in the combination with MMP-9 (stages I and II only). In case of a combined analysis of TIMP-1 and CA 15-3 and other stages (III and IV) in the combination of MMP-9 and CA 15-3, the increase in PPV value can be observed (Table 3$)$.
The predictive value of a negative test result (NPV) in the total group of BC was slightly higher for CA 15-3 (58\%) than for VEGF (55\%) and for MMP-9 (44\%) or TIMP-1 (37\%). The combined use of the tested parameters and antigen CA 15-3 resulted in an increase in the NPV in all cases, for example, with VEGF - to $73 \%$ and with MMP-9 to $65 \%$, but a maximum range was obtained for the combination of all parameters (75\%) (total BC group). The highest NPV in stage I of cancer was observed for VEGF (80\%), in stage II of BC - VEGF and CA 15-3 (82\% both), and in stages III and IV of BC - CA 15-3 (94\% both). The combined use of the tested parameters and antigen CA 15-3 resulted in an increase in the NPV value in every stage of cancer. Maximum equal ranges $(100 \%)$ were obtained for the combination of VEGF and MMP-9 with CA 15-3 in stage III of BC (Table 3).

The relationship between the diagnostic SE and SP is illustrated by the ROC curve. The AUC indicates the clinical usefulness of a tumor marker and its diagnostic power. We noticed that the VEGF area under the ROC curve (0.824) in the total group of BC was larger than the area of MMP-9 (0.678) and TIMP-1 (0.567) and was slightly lower than the AUC of CA 15-3 (0.845). Moreover, the AUCs for VEGF and MMP-9, similarly as for CA 15-3, were statistically significantly larger in comparison to $\mathrm{AUC}=0.5$ (borderline 
Table 4 Diagnostic criteria of ROC curve for tested parameters and CA I5-3

\begin{tabular}{|c|c|c|c|c|}
\hline \multirow[t]{2}{*}{ Tested parameters } & \multicolumn{4}{|c|}{ ROC criteria in breast cancer (total group) } \\
\hline & AUC & SE & $95 \% \mathrm{Cl}(\mathrm{AUC})$ & $P(A \cup C=0.5)$ \\
\hline VEGF & 0.824 & 0.0401 & $0.743-0.901$ & $<0.001$ \\
\hline MMP-9 & 0.678 & 0.0497 & $0.538-0.778$ & $<0.001$ \\
\hline TIMP-I & 0.567 & 0.0547 & $0.462-0.687$ & 0.1952 \\
\hline CA $15-3$ & 0.845 & 0.0365 & $0.776-0.919$ & $<0.001$ \\
\hline VEGF + CA I5-3 & 0.888 & 0.0314 & $0.827-0.950$ & $<0.001$ \\
\hline MMP-9 + CA I5-3 & 0.869 & 0.0337 & $0.799-0.932$ & $<0.001$ \\
\hline TIMP-I + CA I5-3 & 0.847 & 0.0363 & $0.777-0.920$ & $<0.001$ \\
\hline VEGF + MMP-9 + CA I5-3 & 0.897 & 0.0296 & $0.839-0.955$ & $<0.001$ \\
\hline VEGF + TIMP-I + CA I5-3 & 0.889 & 0.0313 & $0.828-0.950$ & $<0.001$ \\
\hline VEGF + MMP-9 + TIMP-I + CA I5-3 & 0.897 & 0.0297 & $0.839-0.955$ & $<0.001$ \\
\hline
\end{tabular}

Note: $P$ - statistically significantly larger AUCs compared to AUC $=0.5$.

Abbreviations: ROC, receiver-operating characteristics; CA, cancer antigen; AUC, area under the ROC curve; SE, standard error; Cl, confidence interval; VEGF, vascular endothelial growth factor; MMP-9, matrix metalloproteinase-9; TIMP-I, tissue inhibitor of metalloproteinase-I.

of the diagnostic usefulness of the test $)(P<0.001$, in all cases). The combined analysis of AUC for VEGF, MMP-9, and TIMP-1 with antigen CA 15-3 resulted in an increase in the areas in all cases $(0.888,0.869$, and 0.847 , respectively), but a maximum range in the total $\mathrm{BC}$ group was obtained for the combination of VEGF, MMP-9, and CA 15-3 (0.897). Additionally, the AUCs in the combined analysis of VEGF, MMP-9, and TIMP-1 with antigen CA 15-3 were statistically significantly larger in comparison to AUC $=0.5$ (Table 4; Figure 1).

\section{Discussion}

Angiogenesis, a physiological process of blood vessel formation, is crucial for tumor progression and nutrition.
VEGF has been demonstrated to be a major contributor to cell proliferation, migration, and it is a potent stimulatory factor of angiogenesis. A high expression of VEGF has been found in body fluids and different kinds of tumors, for example, lung, ${ }^{32,33}$ squamous cell carcinoma of head and neck, ${ }^{34}$ gastric, ${ }^{35,36}$ and colon cancer. ${ }^{37}$

MMPs are a family of human zinc-dependent peptidases. MMP-9 is associated with invasion, metastasis, and poor prognosis in different types of malignancies, for example, endometrial ${ }^{38}$ or lung ${ }^{39,40}$ cancers. The catalytic activity of MMPs can be inhibited by tissue inhibitors of metalloproteinases. A high expression of TIMPs (especially TIMP-1) has been found in esophageal, ${ }^{41}$ pancreatic, ${ }^{42}$ and gastric ${ }^{43}$ cancers.

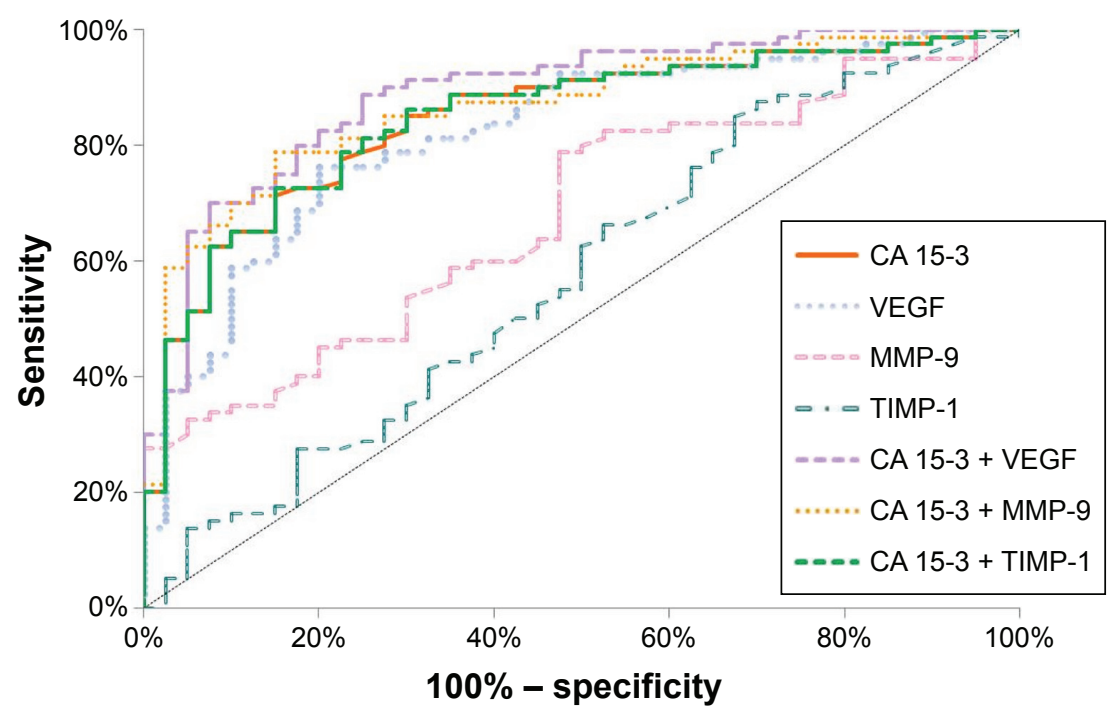

Figure I Diagnostic criteria of ROC curve for tested parameters and in combination with CA I5-3 in total BC group.

Abbreviations: ROC, receiver-operating characteristics; CA, cancer antigen; BC, breast cancer; VEGF, vascular endothelial growth factor; MMP-9, matrix metalloproteinase-9; TIMP-I, tissue inhibitor of metalloproteinase-I. 
According to the studied literature, high serum or plasma levels of VEGF, MMP-9, or TIMP-1 have been observed, for example, in patients with endometrial cancer, ${ }^{38,44-47}$ ovarian cancer, ${ }^{48-50}$ and BC. ${ }^{12,18,21,24,51,52}$

In this study, the plasma levels of VEGF, MMP-9, and CA 15-3 in the total group of patients with $\mathrm{BC}$ were statistically significantly higher when compared with healthy women. Similar significant data were observed in the paper of Rashad et $\mathrm{al},{ }^{53}$ but these authors compared only the plasma levels of MMP-9 in patients with $\mathrm{BC}$ to the healthy control group. Other authors obtained identical results in ovarian cancer. ${ }^{49}$ In the paper of Rashad et al ${ }^{53}$ MMP-9 level was significantly higher in metastatic patients than nonmetastatic patients, which is different than in our results. This discrepancy can be explained by the increase in plasma level of MMP-9 from stage I to III and the decrease from stage III to IV based on the role of this parameter in angiogenesis..$^{53}$ Comparable results for VEGF were observed in our previous study. ${ }^{26}$ In the publications of Ivoino et $\mathrm{al}^{54}$ and Findeisen et $\mathrm{al},{ }^{55}$ significantly higher serum levels of VEGF were observed in patients with $\mathrm{BC}$ than in healthy controls. These results are in accordance with this study and with the results obtained by other researchers, for instance, in gastric ${ }^{41}$ and endometrial cancer. ${ }^{50}$ Contrary to our results, other authors have not found significant differences in the serum levels of VEGF concentrations in early stages of $\mathrm{BC}$ in comparison to identical control groups. ${ }^{56}$ This discrepancy between the results obtained by Duranyildiz et $\mathrm{a}^{56}$ and our study probably resulted from a different composition and size of the group of patients compared. Furthermore, Ivoino et $\mathrm{a}^{54}$ observed a positive relationship between VEGF serum levels and tumor overexpression. In vivo expressions of extracellular VEGF were also significantly higher in $\mathrm{BC}$ tumors than in normal surrounding cells in breast tissue. ${ }^{57}$

We also noticed higher plasma levels for VEGF and TIMP-1 in BC group in comparison to the group with benign lesions (statistical significance). Similar data were observed in our previous study ${ }^{26}$ and in the paper by Xu et al,,$^{58}$ though these authors compared only 45 patients with $\mathrm{BC}$ to 16 patients with benign lesions.

Significant positive Spearman's rank correlations in our study were estimated between CA 15-3 and TIMP-1 levels in the total group and stage I of patients with $\mathrm{BC}$, which indicates a similarity to the commonly used tumor marker. We could not confirm our findings by other publications since no reports on the subject are available. However, in our previous study, ${ }^{26}$ we observed a significant positive correlation between VEGF and CA 15-3. The discrepancy between these results is probably associated with a different size of the compared groups.

In this study, the VEGF SE (61\%) was the highest of all the studied parameters but lower than CA 15-3 (65\%). In the study by Metwally et al, ${ }^{52}$ the SE of CA 15-3 (52.2\%) was comparable and the highest, but the SE of VEGF $(21.3 \%)$ was much lower. Those differences might be related to smaller study groups (44 patients with $\mathrm{BC}$ and only 15 healthy individuals in control group in the study of Metwally et a ${ }^{52}$ ). For MMP-9, we obtained the SE of $37 \%$, and this result was similar to the outcome obtained by Hurst et $\mathrm{al}^{59}$ in colorectal cancer. In case of TIMP-1, the SE obtained by Kozłowski et $\mathrm{al}^{41}$ in esophageal cancer (80\%) was much higher than ours (17\%). This discrepancy between these results is probably associated with different types of cancer and it could be the evidence for high usefulness of TIMP-1 in this type of cancer.

The SP for all the tested parameters in our study was very high and equal $(96 \%)$. Similar data were observed in our previous study on $\mathrm{BC}^{26}$ and in ovarian cancer. ${ }^{28}$ The $\mathrm{SP}$ of VEGF was also investigated by Cao et $\mathrm{ll}^{60}$ in case of lung cancer and was slightly lower (84.2\%) than our result and the one investigated by Bunger et $\mathrm{al}^{37}$ in case of colon cancer. The SP obtained by them (95\%) was almost the same as in our study. MMP-9 SP obtained by Hurst et $\mathrm{al}^{59}$ in the study on colorectal cancer was also very similar (95.8\%). In case of TIMP-1, the SP obtained by Kozłowski et $\mathrm{al}^{49}$ in esophageal cancer $(60 \%)$ was lower than in our study. The discrepancy between these results is probably associated with different types of cancer compared, and it has a higher utility only in certain types of cancer.

The PPV reflects the probability of a disease presence based on a positive result of the test. The NPV indicates the probability of disease exclusion based on a negative test result. In this investigation, VEGF and MMP-9 proved to have very high predictive values (almost the same as CA 15-3) in the total group of patients with $\mathrm{BC}$ and in case of VEGF, higher than CA 15-3 in stage I of BC. Almost the same results for VEGF were observed in comparison to our previous study on $\mathrm{BC}^{26}$ and ovarian cancer ${ }^{28}$ in comparison to CA 125, and this may confirm the key role of this cytokine in the carcinogenesis. Unfortunately, we could not compare our data on $\mathrm{BC}$ since no reports on the subject are available.

The AUC numerically describes the overall performance of a marker, with the AUC indicating a perfect SE and SP. According to this study, the ROC area of VEGF was the largest of all the tested parameters, yet slightly smaller than CA 15-3. Our results showed that the diagnostic power of the tested parameters, especially VEGF, in the group of patients 
with BC was almost the same as the diagnostic power of VEGF in the course of lung cancer studies conducted by Ahmed et $\mathrm{al}^{61}$ and Cao et al, ${ }^{60}$ which indicates a high importance of VEGF in those types of tumor.

\section{Conclusion}

In conclusion, our present results indicate the usefulness of VEGF and MMP-9 in the diagnosis of patients with $\mathrm{BC}$, especially in the combination with CA 15-3. Among the tested parameters, VEGF occurred to be the best candidate for cancer diagnosis especially in stage I of the disease and when combined with CA 15-3 as a new diagnostic panel.

\section{Acknowledgment}

This research was financed by Grants for Medical University of Białystok (numbers 143-07773F and 143-07774F) in the years 2014-2015 from the Polish Ministry of Science and Higher Education.

\section{Disclosure}

The authors report no conflicts of interest in this work.

\section{References}

1. Alvarado R, Lari SA, Roses RE, Smith BD, Yang W, Mittendorf EA. Biology, treatment, and outcome in very young and older women with DCIS. Ann Surg Oncol. 2012;19:3777-3784.

2. Perez-Rivas LG, Jerez JM, Fernandez-De Sousa CE, et al. Serum protein levels following surgery in breast cancer patients: a protein microarray approach. Int J Oncol. 2012;41(6):2200-2206.

3. Bieche I, Lerebours F, Tozlu S, Espie M, Marty M, Lidereau R. Molecular profiling of inflammatory breast cancer: identification of a poorprognosis gene expression signature. Clin Cancer Res. 2004;10(20): 6789-6795.

4. Kufe DW. MUC1-C oncoprotein as a target in breast cancer: activation of signaling pathways and therapeutic approaches. Oncogene. 2013; 32(9):1073-1081.

5. Harris L, Fritsche H, Mennel R, et al; American Society of Clinical Oncology. American Society of Clinical Oncology 2007 update of recommendations for the use of tumor markers in breast cancer. $J$ Clin Oncol. 2007;25:5287-5312.

6. Wang HL, Zhang ZL. Analysis of the relationship between ultrasound of breast cancer DOT-SDI and the expression of MVD, VEGF and HIF-1 $\alpha$. Cell Biochem Biophys. 2014;70(1):205-208.

7. Richardsen E, Uglehus RD, Johnsen SH, Busund LT. Macrophagecolony stimulating factor (CSF1) predicts breast cancer progression and mortality. Anticancer Res. 2015;35(2):865-874.

8. Bottino J, Gelaleti GB, Maschio LB, Jardim-Perassi BV, de Campos Zuccari DA. Immunoexpression of ROCK-1 and MMP-9 as prognostic markers in breast cancer. Acta Histochem. 2014;116(8):1367-1373.

9. Kim GE, Lee JS, Choi YD, et al. Expression of matrix metalloproteinases and their inhibitors in different immunohistochemical-based molecular subtypes of breast cancer. BMC Cancer. 2014;14:959.

10. Schmidt M, Voelker HU, Kapp M, Dietl J, Kammerer U. Expression of VEGFR-1 (Flt-1) in breast cancer is associated with VEGF expression and with node-negative tumour stage. Anticancer Res. 2008;28:1719-1724.

11. Teramoto S, Arihiro K, Koseki M, Kataoka T, Asahara T, Ohdan H. Role of vascular endothelial growth factor-C and -D mRNA in breast cancer. Hiroshima J Med Sci. 2008;57:73-78.
12. Gisterek I, Matkowski R, Lacko A, et al. Serum vascular endothelial growth factor A, C and D in human breast tumors. Pathol Oncol Res. 2010; 16:337-344.

13. García MF, González-Reyes S, González LO, et al. Comparative study of the expression of metalloproteases and their inhibitors in different localizations within primary tumours and in metastatic lymph nodes of breast cancer. Int J Exp Pathol. 2010;91(4):324-334.

14. Mehner C, Hockla A, Miller E, Ran S, Radisky DC, Radisky ES. Tumor cell-produced matrix metalloproteinase 9 (MMP-9) drives malignant progression and metastasis of basal-like triple negative breast cancer. Oncotarget. 2014;5(9):2736-2749.

15. Slattery ML, John E, Torres-Mejia G, et al. Matrix metalloproteinase genes are associated with breast cancer risk and survival: the breast cancer health disparities study. PLoS One. 2013;8(5):e63165.

16. Wu QW, Yang QM, Huang YF, et al. Expression and clinical significance of matrix metalloproteinase-9 in lymphatic invasiveness and metastasis of breast cancer. PLoS One. 2014;9(5):e97804.

17. Zhao S, Ma W, Zhang M, et al. High expression of CD147 and MMP-9 is correlated with poor prognosis of triple-negative breast cancer (TNBC) patients. Med Oncol. 2013;30(1):335.

18. Yousef EM, Tahir MR, St-Pierre Y, Gaboury LA. MMP-9 expression varies according to molecular subtypes of breast cancer. BMC Cancer. 2014;4:609

19. Song J, Su H, Zhou YY, Guo LL. Prognostic value of matrix metalloproteinase 9 expression in breast cancer patients: a meta-analysis. Asian Pac J Cancer Prev. 2013;14(3):1615-1621.

20. Thorsen SB, Christensen SL, Würtz SO, et al. Plasma levels of the MMP-9:TIMP-1 complex as prognostic biomarker in breast cancer: a retrospective study. BMC Cancer. 2013;13:598.

21. Würtz SØ, Schrohl AS, Sørensen NM, et al. Tissue inhibitor of metalloproteinases-1 in breast cancer. Endocr Relat Cancer. 2005;12(2): 215-227.

22. Schrohl AS, Look MP, Meijer-van Gelder ME, Foekens JA, Brünner N. Tumor tissue levels of Tissue Inhibitor of Metalloproteinases-1 (TIMP-1) and outcome following adjuvant chemotherapy in premenopausal lymph node-positive breast cancer patients: a retrospective study. BMC Cancer. 2009;9:322.

23. Schrohl AS, Meijer-van Gelder ME, Holten-Andersen MN, et al. Primary tumor levels of tissue inhibitor of metalloproteinases-1 are predictive of resistance to chemotherapy in patients with metastatic breast cancer. Clin Cancer Res. 2006;12:7054-7058.

24. Lipton A, Ali SM, Leitzel K, et al. Elevated plasma tissue inhibitor of metalloproteinase-1 level predicts decreased response and survival in metastatic breast cancer. Cancer. 2007;109:1933-1939.

25. Lipton A, Leitzel K, Chaudri-Ross HA, et al. Serum TIMP-1 and response to the aromatase inhibitor letrozole versus tamoxifen in metastatic breast cancer. J Clin Oncol. 2008;26:2653-2658.

26. Ławicki S, Będkowska GE, Szmitkowski M. VEGF, M-CSF and CA 15-3 as a new tumor marker panel in breast malignancies: a multivariate analysis with ROC curve. Growth Factors. 2013;31(3):98-105.

27. Ławicki S, Będkowska GE, Wojtukiewicz M, Szmitkowski M. Hematopoietic cytokines as tumor markers in breast malignancies. A multivariate analysis with ROC curve in breast cancer patients. Adv Med Sci. 2013;58(2):207-215.

28. Ławicki S, Będkowska GE, Gacuta-Szumarska E, Szmitkowski M. The plasma concentration of VEGF, HE4 and CA125 as a new biomarkers panel in different stages and sub-types of epithelial ovarian tumors. J Ovarian Res. 2013;6(1):45.

29. Ławicki S, Gacuta-Szumarska E, Będkowska GE, Szmitkowski M. Hematopoietic cytokines as tumor markers in gynecological malignancies. A multivariate analysis in epithelial ovarian cancer patients. Growth Factors. 2012;30(6):357-366.

30. Ławicki S, Będkowska GE, Gacuta-Szumarska E, Knapp P, Szmitkowski M. Pretreatment plasma levels and diagnostic utility of hematopoietic cytokines in cervical cancer or cervical intraepithelial neoplasia patients. Folia Histochem Cytobiol. 2012;50(2): 213-219. 
31. Ławicki S, Będkowska GE, Gacuta-Szumarska E, Szmitkowski M. Hematopoietic cytokines as tumor markers in gynecological malignancies: a multivariate analysis with ROC curve in endometrial cancer patients. Growth Factors. 2012;30(1):29-36.

32. Carrillo-de Santa Pau E, Carrillo Arias F, Caso Pelaez E, et al. Vascular endothelial growth factor (VEGF) serum levels are associated with survival in early stages of lung cancer patients. Cancer Invest. 2010;28:393-398.

33. Honguero Martínez AF, Arnau Obrer A, Figueroa Almazán S, Martínez Hernández N, Guijarro Jorge R. Prognostic value of the expression of vascular endothelial growth factor A and hypoxia-inducible factor 1alpha in patients undergoing surgery for non-small cell lung cancer. Med Clin (Barc). 2014;142(10):432-437.

34. Srivastava VK, Gara RK, Rastogi N, et al. Serum vascular endothelial growth factor-A (VEGF-A) as a biomarker in squamous cell carcinoma of head and neck patients undergoing chemoradiotherapy. Asian Pac J Cancer Prev. 2014;15(7):3261-3265.

35. Halmaciu I, Gurzu S, Dobreanu M, Suciu BA, Brinzaniuc K. Preliminary results regarding vascular endothelial growth factor (VEGF-A) levels in the serum of gastric cancer patients. Rev Med Chir Soc Med Nat Iasi. 2012;116:446-451.

36. Villarejo-Campos P, Padilla-Valverde D, Martin RM, et al. Serum VEGF and VEGF-C values before surgery and after postoperative treatment in gastric cancer. Clin Transl Oncol. 2013;15(4):265-270.

37. Bunger S, Haug U, Kelly FM, et al; BMBF-Consortium "Colorectal Cancer Screening Chip. Toward standardized high-through put serum diagnostics: multiplex-protein array identifies IL-8 and VEGF as serum markers for colon cancer. J Biomol Screen. 2011;16:1018-1026.

38. Weigel MT, Krämer J, Schem C, et al. Differential expression of MMP-2, MMP-9 and PCNA in endometriosis and endometrial carcinoma. Eur J Obstet Gynecol Reprod Biol. 2012;160(1):74-78.

39. El-Badrawy MK, Yousef AM, Shaalan D, Elsamanoudy AZ. Matrix metalloproteinase-9 expression in lung cancer patients and its relation to serum mmp-9 activity, pathologic type, and prognosis. J Bronchology Interv Pulmonol. 2014;21(4):327-334.

40. Tang ZP, Cui QZ, Dong QZ, Xu K, Wang EH. Ataxia-telangiectasia group D complementing gene (ATDC) upregulates matrix metalloproteinase 9 (MMP-9) to promote lung cancer cell invasion by activating ERK and JNK pathways. Tumour Biol. 2013;34(5):2835-2842.

41. Kozłowski M, Laudański W, Mroczko B, Szmitkowski M, Milewski R, Łapuć G. Serum tissue inhibitor of metalloproteinase 1 (TIMP-1) and vascular endothelial growth factor A (VEGF-A) are associated with prognosis in esophageal cancer patients. Adv Med Sci. 2013;58(2):227-234.

42. Poruk KE, Firpo MA, Scaife CL, et al. Serum osteopontin and tissue inhibitor of metalloproteinase 1 as diagnostic and prognostic biomarkers for pancreatic adenocarcinoma. Pancreas. 2013;42(2):193-197.

43. Grunnet M, Mau-Sørensen M, Brünner N. Tissue inhibitor of metalloproteinase 1 (TIMP-1) as a biomarker in gastric cancer: a review. Scand J Gastroenterol. 2013;48(8):899-905.

44. Dobrzycka B, Terlikowski SJ, Kowalczuk O, Kulikowski M, Niklinski J Serum levels of VEGF and VEGF-C in patients with endometrial cancer. Eur Cytokine Netw. 2011;22:45-51.

45. Piastowska-Ciesielska AW, Płuciennik E, Wójcik-Krowiranda K, Bieńkiewicz A, Bednarek A, Ochędalski T. Analysis of the expression of angiotensin II type 1 receptor and VEGF in endometrial adenocarcinoma with different clinicopathological characteristics. Tumour Biol. 2012; 33:767-774

OncoTargets and Therapy

\section{Publish your work in this journal}

OncoTargets and Therapy is an international, peer-reviewed, open access journal focusing on the pathological basis of all cancers, potential targets for therapy and treatment protocols employed to improve the management of cancer patients. The journal also focuses on the impact of management programs and new therapeutic agents and protocols on
46. HonkavuoriM, Talvensaari-Mattila A,Puistola U, Turpeenniemi-Hujanen T, Santala M. High serum TIMP-1 is associated with adverse prognosis in endometrial carcinoma. Anticancer Res. 2008;28(5A):2715-2719.

47. Grybos A, Bar J. The relationships between the immunoexpression of KAI1, MMP-2, MMP-9 and steroid receptors expression in endometrial cancer. Folia Histochem Cytobiol. 2014;52(3):187-194.

48. Sadłecki P, Walentowicz-Sadłecka M, Szymański W, Grabiec M. Comparison of VEGF, IL-8 and beta-FGF concentrations in the serum and ascites of patients with ovarian cancer. Ginekol Pol. 2011;82: 498-502.

49. Li LN, Zhou X, Gu Y, Yan J. Prognostic value of MMP-9 in ovarian cancer: a meta-analysis. Asian Pac J Cancer Prev. 2013;14(7):4107-4113.

50. Hu X, Li D, Zhang W, Zhou J, Tang B, Li L. Matrix metalloproteinase-9 expression correlates with prognosis and involved in ovarian cancer cell invasion. Arch Gynecol Obstet. 2012;286(6):1537-1543.

51. Berezov TT, Ovchinnikova LK, Kuznetsova OM, et al. Vascular endothelial growth factor in the serum of breast cancer patients. Bull Exp Biol Med. 2009;148:419-424.

52. Metwally FM, El-mezayen HA, Ahmed HH. Significance of vascular endothelial growth factor, interleukin-18 and nitric oxide in patients with breast cancer: correlation with carbohydrate antigen 15.3. Med Oncol. 2011;28:15-21.

53. Rashad YA, Elkhodary TR, El-Gayar AM, Eissa LA. Evaluation of serum levels of HER2, MMP-9, nitric oxide, and total antioxidant capacity in Egyptian breast cancer patients: correlation with clinicopathological parameters. Sci Pharm. 2013;82(1):129-145.

54. Ivoino F, Ferraraccio F, Orditura M, et al. Serum vascular endothelial growth factor (VEGF) levels correlate with tumor VEGF and p53 overexpression in endocrine positive primary breast cancer. Cancer Invest. 2008;26:250-255.

55. Findeisen R, Albrecht S, Richter B, Deutschmann K, Zimmermann T, Distler W. Chemiluminometric determination of tissue polypeptide antigen (TPA), cancer antigen 15-3 (CA 15-3), carcinoembryonic antigen (CEA) in comparison with vascular endothelial growth factor (VEGF) in follow-up of breast cancer. Luminescence. 2000;15:283-289.

56. Duranyildiz D, Camlica H, Soydinc HO, Derin D, Yasasever V. Serum levels of angiogenic factors in early breast cancer remain close to normal. Breast. 2009;18:26-29.

57. Garvin S, Dabrosin C. In vivo measurement of tumor estradiol and vascular endothelial growth factor in breast cancer patients. $B M C$ Cancer. 2008;8:73-78.

58. Xu N, Lei Z, Li XL, et al. Clinical study of tumor angiogenesis and perfusion imaging using multi-slice spiral computed tomography for breast cancer. Asian Pac J Cancer Prev. 2013;14(1):429-433.

59. Hurst NG, Stocken DD, Wilson S, Keh C, Wakelam MJ, Ismail T. Elevated serum matrix metalloproteinase 9 (MMP-9) concentration predicts the presence of colorectal neoplasia in symptomatic patients. Br J Cancer. 2007;97(7):971-977.

60. Cao C, Sun SF, Lv D, Chen ZB, Ding QL, Deng ZC. Utility of VEGF and sVEGFR-1 in bronchoalveolar lavage fluid for differential diagnosis of primary lung cancer. Asian Pac J Cancer Prev. 2013;14(4): 2443-2446.

61. Ahmed MB, Nabih ES, Louka ML, Abdel Motaleb FI, El Sayed MA, Elwakiel HM. Evaluation of nestin in lung adenocarcinoma: relation to VEGF and Bcl-2. Biomarkers. 2014;19(1):29-33.

\section{Dovepress}

patient perspectives such as quality of life, adherence and satisfaction. The manuscript management system is completely online and includes a very quick and fair peer-review system, which is all easy to use. Visit http://www.dovepress.com/testimonials.php to read real quotes from published authors. 